\title{
Depth profiling of ceramic coatings and nitrided steels with UV laser ablation inductively coupled plasma atomic emission spectrometry
}

\author{
V. KANICKÝ ${ }^{(1)}$, I. NOVOTNÝ( ${ }^{(1)}$, J.L. LACOUR* ${ }^{*}$ P. MAUCHIEN* and J.M. MERMET \\ Laboratoire des Sciences Analytiques, Bât. 308, Université Claude Bernard Lyon I, 69622 Villeurbanne \\ cedex, France \\ * Laboratoire de Spectroscopie Laser Analytique, DPE/SPEA, CE Saclay, Bât. 391, 91191 Gif sur Yvette, \\ France
}

A development of technologies involved in hard ceramic coating deposition on metal substrates requires special analytical methods for the determination of both the bulk composition and the depth profiles of elemental concentrations. Currently, laser ablation seems to be an attractive technique for the layer-by-layer sampling of both conductive and non-conductive materials. A study of depth profiling of two different samples of ceramic coatings and two samples of nitrided steel has been conducted. Ablated material was introduced into an inductively coupled plasma (ICP) for further volatilization, atomization and excitation. Atomic emission spectrometry (AES) was used as the method of analysis. The state of the ablated surface was studied by means of a profilemeter and microphotographies. Information was therefore obtained on the shape and the depth of the craters. Formation of the microplasma on the surface of the target was studied by using an intensified, gated CCD camera with a gate duration of $3 \mathrm{~ns}$.

Ceramic coatings were prepared using plasma spray deposition 1,2. Partially stabilized zirconia coatings $\left(\mathrm{ZrO}_{2}-\mathrm{PSZ}\right)$ were deposited as graded materials - ceramic coatings (GMC) on an inconel steel substrate. Composition and thickness of the coatings were: $\mathrm{ZrO}_{2}-8 \% \mathrm{Y}_{2} \mathrm{O}_{3}(420 \mu \mathrm{m})$, GMC $(190 \mu \mathrm{m})$, NiCrAlY alloy $(90 \mu \mathrm{m})$ for the first sample and $\mathrm{ZrO}_{2}-25 \% \mathrm{CeO}_{2}(410 \mu \mathrm{m}), \mathrm{GMC}(220 \mu \mathrm{m})$, NiCrAlY alloy $(90 \mu \mathrm{m})$ for the second sample. Titanium was sputtered on the surface of one nitrided steel and vanadium on the other one during nitrification. Ablation was performed by using a frequency-tripled, Q-switched Nd:YAG laser $(355 \mathrm{~nm}$ ) and detection was obtained using the Spectro D and Perkin Elmer Optima 3000 ICP systems. Results will be described on the efficiency of ablation related to the intensity and shape of the microplasma, and the capability of depth profiling according to the composition of the coating.

1. J. Musil and J. Fiala, Surface and Coatings Technology, 211, 52 (1992).

2. J. Musil, I. Stepanek, J. Musil Jr and M. Kolega, Materials Science and Engineering, 211, A163 (1993).

(1) Present address: Masaryk University, Brno, Czech Republic 